\title{
Herpes simplex (Buttockalis) of the buttock is a variant of herpes simplex genitalis
}

\author{
Khalifa E. Sharquie', Wesal K. Al-Janabi ${ }^{2}$
}

\author{
${ }^{1}$ Department of Dermatology, College of Medicine, University of Baghdad, Iraqi and Arab Board for Dermatology \& \\ Venereology, Baghdad Teaching Hospital, Medical City, Baghdad, Iraq, ${ }^{2}$ Dermatology Center, Medical City, Baghdad, Iraq
}

Corresponding author: Prof. Khalifa E. Sharquie, E-mail: ksharquie@ymail.com

\begin{abstract}
Background: Herpes simplex virus 1 and 2 typically cause infections of the oral and genital mucosa, respectively. Extraoral and extra-genital sites are not infrequently involved. Herpes simplex infection of buttock is not well documented in medical literature. Aim: To report cases of herpes simplex on buttock and raise a question about its relation with anal sex. Materials and Methods: This study was conducted at the Dermatology Center, Baghdad Medical City, Baghdad, Iraq during the period from December 2005 to September 2019. All the cases of herpes simplex infection on buttocks were evaluated for the demographic data and clinical features. Results: Nine patients with herpes simplex on the buttocks so called herpes simplex buttockalis, five males and four females were included in this study (male: Female ratio $=1.2: 1$ ). The mean age was $32.1 \pm 10.37$ years. All patients gave history of recurrent similar attacks at same sites or on the adjacent areas but no concomitant genital herpes except in one patient. No one gave history of anal or orogenital sex. Regarding the sites affected: left upper medial quadrant was the affected part in 3 male patients with one had left upper lateral quadrant also involved, two patients (one female and one male) had the lesions on the right upper medial quadrant, two patients had right lower medial quadrant lesions (one male and one female with cleft also), one female had lesion only in the upper left gluteal cleft area while one female with right upper lateral quadrant lesion. No regional lymphadenopathy was detected. Areas innervated by the sensory nerves from sacral ganglia were the most frequently affected ones. Conclusion: Herpes simplex infection of the buttock is not uncommon problem but rarely recognized by doctors or misdiagnosed as herpes zoster especially during the first attack. It can follow any vaginal, anal or oro-genital sexual practice. These cases should not be missed as to avoid infection of partner and to give the right management. This is the first reported study paying attention to this new variant of genital herpes infection of the buttock which deserve the name herpes simplex buttockalis.
\end{abstract}

Key words: Herpes simplex; Genital; Buttock; Iraq

\section{INTRODUCTION}

Herpes simplex viruses (HSVs) are common human DNA viral pathogens that intermittently reactivate causing typical infection. After replication in the skin or mucosa, the virus infects the local nerve endings and ascends to the ganglia where it becomes latent infection until reactivation [1]. There are two types of HSV: HSV-l and HSV-2. HSV-1 is mostly associated with orofacial disease, whereas HSV-2 usually causes genital infection $[1,2]$, but both can infect oral and genital areas and cause acute and recurrent infections.
Most of the adult population is seropositive for HSV-l and the majority of infections are acquired in childhood $[1,3]$ While a study showed that about onefourth of adults are infected with HSV-2. Acquisition of HSV-2 correlates with sexual behavior [1]. Although HSV-2 remains the major cause of recurrent genital herpes infections (70-90\% overall)2, the proportion due to HSV-1 has been increasing in the US, Canada, and the UK. In these countries, HSV-1 now accounts for the majority of genital herpes infections in young adults, especially college students [4,5]. As with other sexually transmitted infections, the rate of acquisition

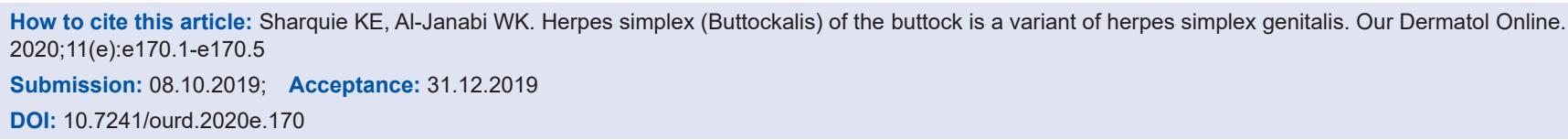


of HSV-2 infection is higher for women than for men. Asymptomatic HSV-2 infection is more common among men and persons who are also seropositive for HSV-1, suggesting that prior infection with HSV-1 reduces one's likelihood of experiencing symptomatic HSV-2 infection [6]. Although genital herpes is the major clinical presentation of HSV-2 infection, but HSV-l is becoming a more common cause of genital herpes in young women $[4,7]$. Because of their epidemiology, acquisition of HSV-1 in a person with prior HSV-2 infection is unusual, but HSV-2 acquisition in the presence of previous HSV-1 infection is common, and infection of the genital tract with both HSV-l and HSV-2 has been described. Patients with previously known HSV-l genital infection who develop frequent genital herpes recurrences should be tested for HSV-2 infection [1]. The virus infects a susceptible person through contact with mucous membranes or open, abraded skin [8]. factors associated with acquisition of genital herpes include an age of 15-30 years (period of greatest sexual activity), an increased number of sexual partners, lower levels of income and education, and HIV- positivity; conversely, genital HSV-2 infection also increases the risk of acquiring and transmitting HIV infection [4]. Most infections are recurrent, with subsequent episodes reappearing at or near the same anatomical location [8]. The outbreaks can occur either spontaneously or triggered by trauma, ultraviolet light, temperature extremes, emotional stress, menstruation, dental or surgical procedures or immunosuppression [8,9]. Most primary HSV infections are asymptomatic or not recognized, but can cause severe disease. Most recurrences are not symptomatic and most transmissions occur during asymptomatic shedding [1]. The progression of classical herpes lesions has been divided according to the following stages based on their features: prodromal, erythema, and papule (the developmental stage); vesicle, ulcer (with a characteristic scalloped border), and hard crust (disease stage); followed by dry flaking and residual swelling (resolution stage) $[1,9]$. It frequently leaves a residual area of discoloration [8]. Herpetic gingivostomatitis and pharyngitis are most commonly associated with a primary HSV-l infection. Other common symptoms include fever, malaise, myalgia, pain on swallowing, irritability, and cervical adenopathy. Reactivation of virus from these primary infections involves the perioral facial area, mainly the lips, with the outer one-third of the lower lip being the most commonly affected area. Other facial locations include the nose, chin, and cheek, and account for fewer than $10 \%$ of cases (Fig. 1). Two- thirds of labial lesions involve the vermilion border, and the rest occur at the junction of the border with the skin [1]. The clinical course of acute first-episode genital herpes among patients with HSV-1 and HSV2 infections is similar that may require 2 to 3 weeks to resolve. In males, lesions commonly occur on the glans penis or the penile shaft and the buttocks are occasionally affected [1,9], (Fig. 2). In females, lesions may involve the vulva, perineum, buttocks, vagina, or cervix. There is accompanying pain, itching, dysuria, vaginal and urethral discharge, and tender inguinal lymphadenopathy. Systemic signs and symptoms are common and include fever, headache, malaise, and myalgia. Herpetic sacral radiculomyelitis with urinary retention, neuralgias, and constipation, can occur. HSV cervicitis occurs in more than $80 \%$ of women with primary infection. It can present as purulent or bloody vaginal discharge; examination reveals areas of diffuse or focal friability and redness, extensive ulcerative lesions of the exocervix, or, rarely, necrotic

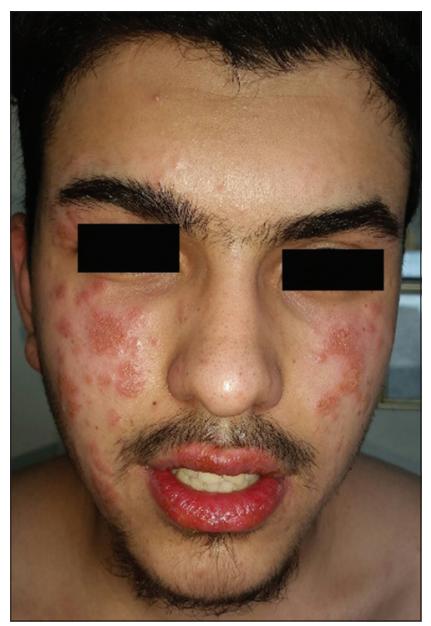

Figure 1: Twenty years male patien with herpes simplex of face and lips.

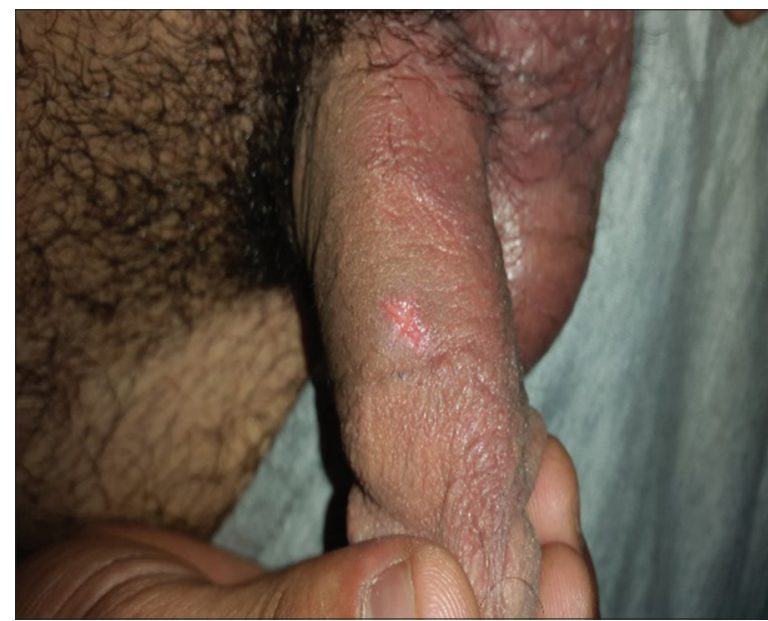

Figure 2: Twenty years male patient with penile herpetic lesions. 
cervicitis. Cervical discharge is usually mucoid, but it is occasionally mucopurulent [1]. Systemic complaints and complications are more common in females [9].

In Iraqi population, we have all different types of herpes simplex whether oral, extra-oral, genital or extragenital but surprisingly, young children commonly have infection of cheeks and rarely lips and usually recurrent on same or different nearby sites and not uncommonly ends with obvious scarring (Fig. 3). Those recurrent attacks might continue for few to several years usually in winter times and then fade up spontaneously (Sharquie personal communication 2016). But these observations were not previously reported in English medical literatures.

\section{MATERIAL AND METHODS}

This study was conducted at the Dermatology Center, Baghdad Medical City, Baghdad, Iraq during the period from December 2005 to September 2019. All the cases of herpes simplex viral infection on buttocks were collected and evaluated for the demographic data like age, gender, and any history of herpetic genital lesion or similar recurrent conditions at same or nearby sites, accompanying itching, burning or tingling sensation, type of sex whether vaginal, anal, vagino-anal or orogenital, history of partner herpes infection. Clinical features of buttock rash, concomitant genital lesions, regional lymphadenopathy and associated systemic symptoms were assessed.

\section{RESULTS}

Nine patients with herpes simplex on the buttocks (Figs. 4-6), five males and four females were included in the study (male: Female ratio $=1.2: 1$ ). The mean age was $32.1 \pm 10.37$ years. All patients gave history of recurrent similar attacks at same sites or nearby area. No one gave history of anal sex.Prodromal symptoms in form of fever, local discomfort, pain and paresthesia. One male patient had concomitant genital lesions by the time of examination. Left upper medial quadrant was the affected part in 3 male patients with one had left upper lateral quadrant also involved. Two patients (one female and one male) had the lesions on the right upper medial quadrant. Two patients (one male and one female with cleft also) with right lower medial quadrant lesions. One female had lesion only in the upper gluteal cleft area. One female with right upper lateral quadrant lesion. No regional lymphadenopathy

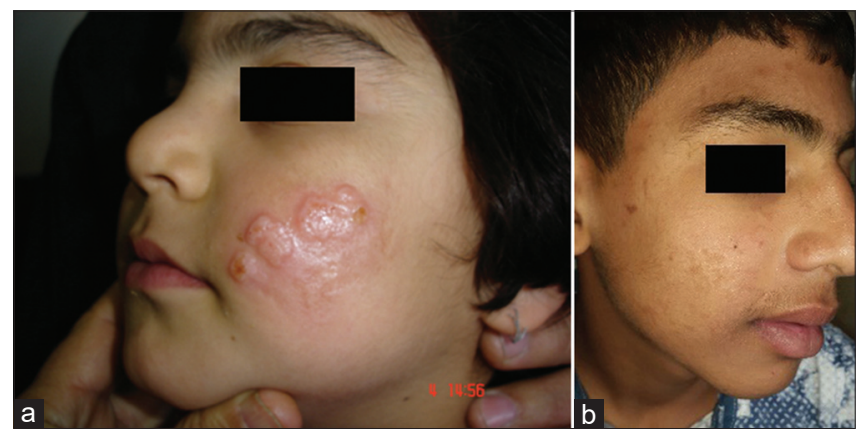

Figure 3: (a) Recurrent herpes simplex viral infection in 8 years female patient superimposed on top of scarring from previous attacks. (b) Fourteen years male patient with evident scarring following recurrent herpes simplex facialis attacks.

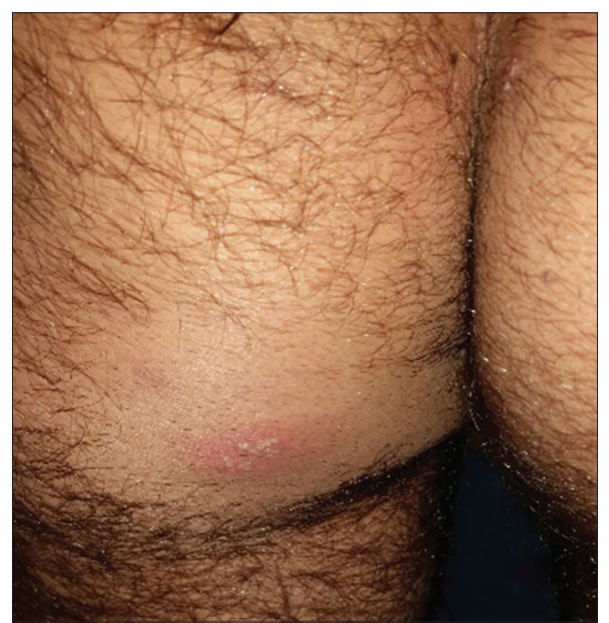

Figure 4: Thirty-eight years male patient with left lower medial buttock's quadrant herpes simplex infection.

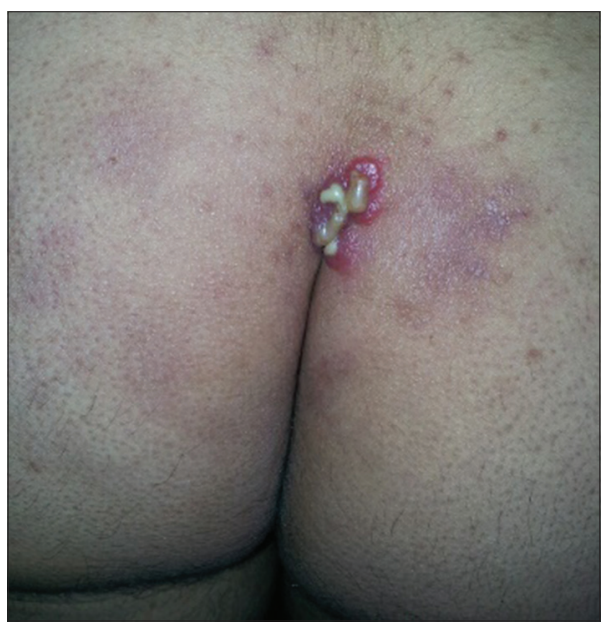

Figure 5: Thirty-five years female patient with herpes simplex lesion at the upper gluteal cleft.

was detected. Regarding sensory root ganglion involved according to the well-known dermatome of skin, three cases occurred on area innervated by the $1^{\text {st }}$ sacral root ganglia, two cases showed $2^{\text {nd }}$ sacral root ganglia related nerve viral reactivation, in another 2 cases area supplied 
by $1^{\text {st }} 4^{\text {th }}$ sacral root ganglia was involved. While one case had both $2^{\text {nd }}$ and $3^{\text {rd }}$ sacral nerve root possible infection and one other case affected area innervated by the sacral $3^{\text {rd }}$ and $4^{\text {th }}$ sensory nerve root ganglia.

\section{DISCUSSION}

In the present study, the mean age of patients was 32.1 yrs. that is compatible to worldwide age distribution for genital herpes $[1,9]$. The buttocks represent a common location in women in few reported cases [9], but the present work showed nearly equal gender affection (male: Female was 1.2:1). Non-oral and non-genital sites are not infrequently involved, possibly due to self-inoculation, primary acquisition, or viremic spread [10]. Although recurrences predominantly occur at the same location, studies have shown that $21 \%$ of patients with primary genital herpes develop non-genital involvement [11]. The sites most often affected are the lumbosacral area and legs, as the pudendal nerve, which innervates the external genitalia, originates from the sacral nerve ganglia of S2-4 which supply the genitalia, anal region and buttocks (Figs. 7 and 8) [11-14]. The areas innervated by the sacral nerve ganglia were the most frequently affected ones.

The present study does suggest that genital herpes can involve any areas in relation of the pudenda nerve distribution like genital areas, groins and buttocks. Although herpes simplex buttockalis is not rare problem but often over looked and go undiagnosed. So any herpetic rash on the buttock areas should be considered genital herpes unless prove otherwise to avoid infection of other partner. But if it is the first attack, herpes zoster might be considered as a diagnosis. Recurrences of HSV-2 lesions on the buttocks occur less frequently than genital recurrences but tend to last longer, thus making intermittent rather than suppressive therapy possible $[11,15]$.

Herpes simplex genitalis among young children including infants is well documented in medical literatures and often claim sexual abuse as a source, while in Iraqi cases, most parents deny sexual abuse. On looking at the cultural behaviors of mother's, we noticed that these mothers often kiss the genitalia of their children, which could result in a direct inoculation from orolabial herpes into genitalia of children (Fig. 9). In addition, herpes infection of newly born infants might occur during delivery from infected mothers that might appear in infancy [16-19]. This observation in Iraqi patients goes with a result of review article about the evidence for the likelihood of sexual transmission in a child with proven genital herpes.

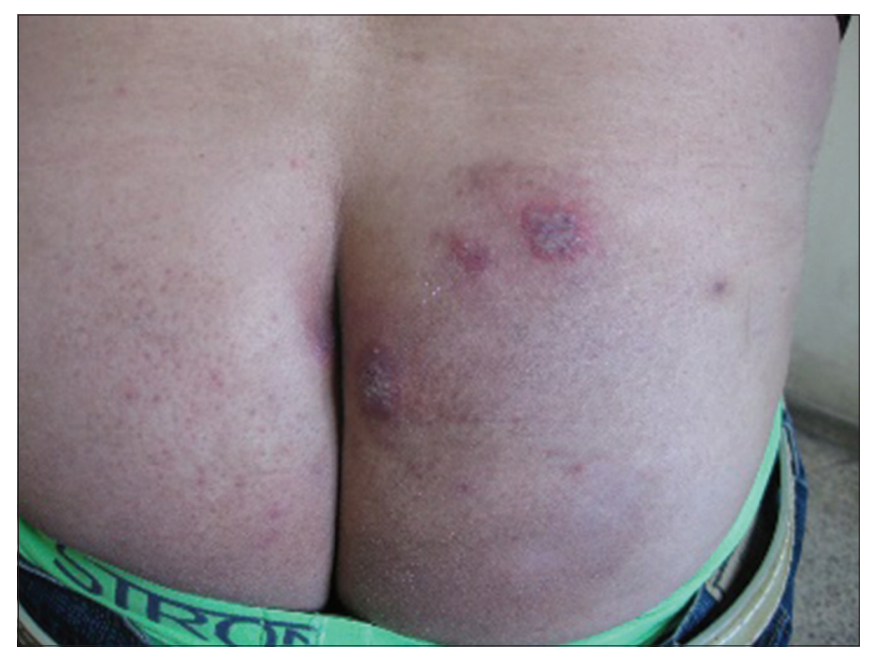

Figure 6: Twenty-five years male patient with herpes on right upper medial buttock quadrant.

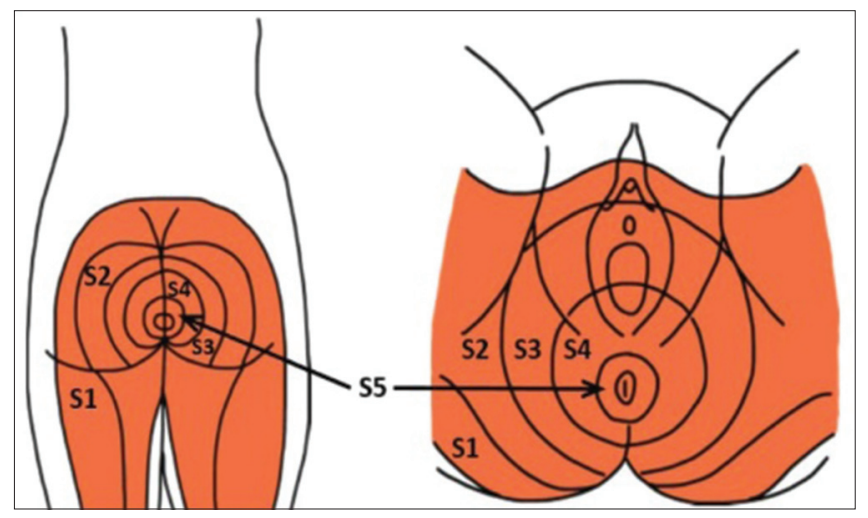

Figure 7: Distribution of sacral nerve ganglia dermatomes within the perineal region [14].

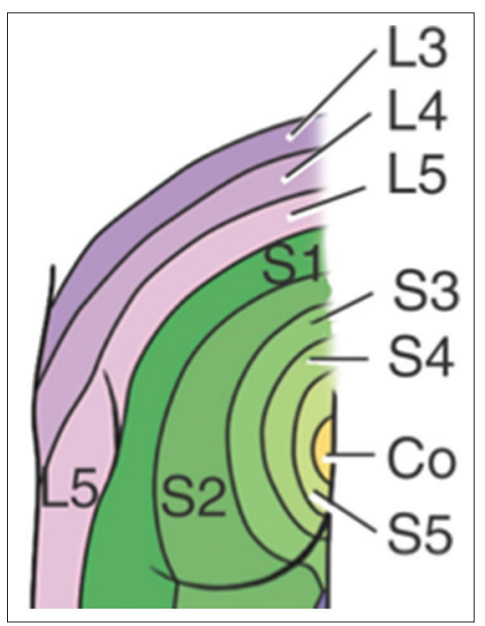

Figure 8: Dermatomes of lower limbs (Gluteal region anatomy). https:// www.memorangapp.com/flashcards/54191/Gluteal+Region+Anatomy/

The review showed that although just over half of reported cases of genital herpes in children had evidence suggestive of a sexual mode of transmission, the quality of assessment of possible sexual abuse was too weak to enable any 
www.odermatol.com

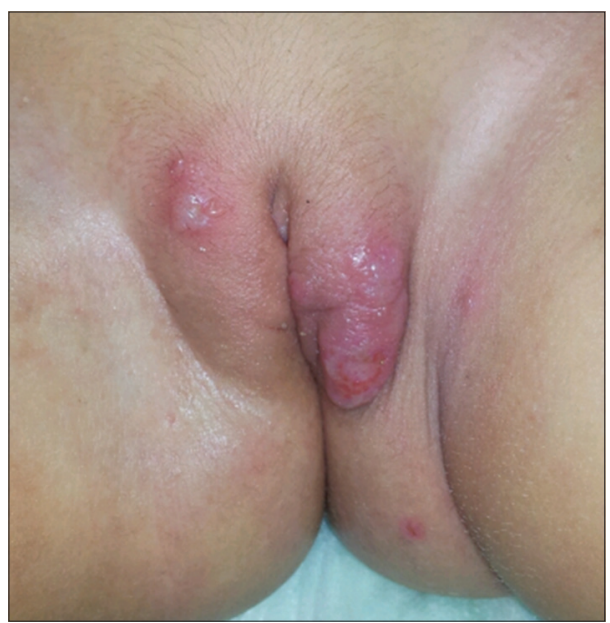

Figure 9: Four years female child with genito-labial herpes simplex and coexisting facial lesions.

reliable estimation of its likelihood. Sexual transmission is reported more commonly in older children (aged $\geqslant 5$ years); in children presenting with genital lesions alone and where type 2 herpes simplex virus is isolated. Hence, they concluded that in order to protect these children to be accused, clinicians should be aware of the weakness of the evidence on the likelihood of sexual transmission of genital herpes prepubertal children [20].

\section{CONCLUSION}

Herpes simplex buttockalis is not a rare variant of herpes genitalis that can follow any vaginal, anal or orogenital sexual practice as these areas are supplied by one pudendal nerve. Doctor should consider any herpetic rash on the buttock as genital herpes and management should go on this direction so as not to miss these cases and to avoid the infection of partner.

\section{Statement of Human and Animal Rights}

All procedures followed were in accordance with the ethical standards of the responsible committee on human experimentation (institutional and national) and with the Helsinki Declaration of 1975 , as revised in 2008 .

\section{Statement of Informed Consent}

Informed consent was obtained from all patients for being included in the study.

\section{REFERENCES}

1. Cohen JI. Herpes Simplex. Kang S, Amagai M, Bruckner A, Enk A, Margolis D, Mc Michael A, et al. Fitzpatrick's Dermatology $9^{\text {th }}$ ed.
2019. 164:3021-34.

2. Mustafa M, Illzam EM, Muniandy RK, Sharifah AM, Nang MK, Ramesh B. Herpes simplex virus infections, Pathophysiology and management. J Dent Med Scien. 2016;7:85-91.

3. Crimi S, Fiorillo L, Bianchi A, D'Amico C, Amoroso G, Gorassini F, et al. Herpes virus, oral clinical signs and QoL: Systematic review of recent data. Viruses. 2019;11:463.

4. Lou Y, Qesmi R, Wang Q, Steben M, Wu J, Heffernan JM. Epidemiological impact of a genital herpes type 2 vaccine for young females. PLoS One. 2012;7:e46027.

5. Aslam M, Kropp RY, Jayaraman G, Dinner K, Wong T, Steben M. Genital herpes in Canada: Deciphering the hidden epidemic. Can J Infect Dis Med Microbiol. 2012;23:e6-e9.

6. Woestenberg PJ, Tjhie JH, de Melker HE, van der Klis FRM, van Bergen JEAM, van der Sande MAB, et al. Herpes simplex virus type 1 and type 2 in the Netherlands: seroprevalence, risk factors and changes during a 12 -year period. BMC Infect Dis. 2016;16:364.

7. Pereira VS, Moizeis RN, Fernandes TA, Araújo JM, Meissner RV, Fernandes JV. Herpes simplex virus type 1 is the main cause of genital herpes in women of Natal, Brazil. Eur J Obstet Gynecol Reprod Biol. 2012;161:190-3.

8. Mendoza N, Madkan V, Sra K, Willison B, Morrison LK, Tyring SK. Human herpesviruses. In: Bolognia JL, Schaffer JV, editors. Dermatology. London: Elsevier Saunders; 2012.

9. Downing C, Mendoza N, Sra K, Tyring SK. Human herpes viruses. In: Bolognia JL, Schaffer JV, Cerony L Dermatology $4^{\text {th }}$ ed. London: Elsevier Saunders; 2018.1400-7.

10. Eksomtramage T, Aiempanakit K. Recurrent extragenital herpes simplex type 2 occurring in a distal location of the same dermatome. IDCases. 2020;21:e00783.

11. Maroñas-Jiménez L, Menis D, Delgado-Márquez AM, Zarco-Olivo C, Ortiz de Frutos FJ. Primary herpes simplex infection with genital and extra-genital lesions mimicking disseminated gonococcal disease. Br J Dermatol. 2015;172:278-80.

12. Ooi C, Zawar V. Hyperaesthesia following genital herpes: a case report. Dermatol Res Pract. 2011;2011:903595.

13. Grekin JA, Mehregan DA. Sacral zoster with a primary complaint of difficulty voiding. JAAD Case Rep. 2017;3:509-11.

14. Vassantachart J, BS and Menter A. Recurrent lumbosacral herpes simplex virus infection. Proc (Bayl Univ Med Cent). 2016;29:48-9.

15. Sauerbrei A. Optimal management of genital herpes: current perspectives. Infect Drug Resist. 2016;9:129-41.

16. Harris JB, Holmes AP. Neonatal Herpes Simplex Viral infections and acyclovir: An update. J Pediatr Pharmacol Ther. 2017;22:88-93.

17. James SH, Kimberlin DW. Neonatal herpes simplex virus infection: epidemiology and treatment. Clin Perinatol. 2015;42:47-viii.

18. Toutous-Trellu L, Vantieghem KM, Terumalai K, Herrmann FR, Piguet V, Kaiser L, et al. Cutaneous lumbosacral herpes simplex virus among patients hospitalized for an advanced disease. J Eur Acad Dermatol Venereol. 2012;26:417-22.

19. Allen UD, Robinson JL, Canadian Paediatric Society. Infectious Diseases and Immunization Committee Prevention and management of neonatal herpes simplex virus infections. Paediatr Child Health. 2014;19:201-6.

20. Vrolijk-Bosschaart TF, Brilleslijper-Kater SN, Widdershoven GA, Teeuw ARH, Verlinden E, Voskes Y, et al. Physical symptoms in very young children assessed for sexual abuse: a mixed method analysis from the ASAC study. Eur J Pediatr. 2017;176:1365-74.

Copyright by Khalifa E. Sharquie, et al. This is an open-access article distributed under the terms of the Creative Commons Attribution License, which permits unrestricted use, distribution, and reproduction in any medium, provided the original author and source are credited.

Source of Support: Nil, Conflict of Interest: None declared. 